\title{
Using a Visualized Reaction-Time Task to Assess Implicit Cognition in Brazilian and Japanese-Descendant Children
}

\author{
Ana Carolina Monnerat Fioravanti-Bastos ${ }^{1}$, Alberto Filgueiras ${ }^{2,3} \&$ J. Landeira-Fernandez ${ }^{2}$ \\ ${ }^{1}$ Department of Psychology, Federal Fluminense University_PURO, Rio das Ostras, Brazil \\ ${ }^{2}$ Department of Psychology, Pontifical Catholic University of Rio de Janeiro, Rio de Janeiro, Brazil \\ ${ }^{3}$ Communication Sciences and Disorders, Western University, London, ON, Canada \\ Correspondence: Ana Carolina Monnerat Fioravanti-Bastos, Alameda Carolina 18/1502, Icaraí, Niterói, RJ, \\ 24230-140, Brazil. Tel: 55-22-2764-9604. E-mail: ana@fioravantiana.org
}

Received: February 11, 2014

Accepted: June 23, $2014 \quad$ Online Published: July 30, 2014

doi:10.5539/ijps.v6n3p80

URL: http://dx.doi.org/10.5539/ijps.v6n3p80

\begin{abstract}
Empirical evidence gathered among different cultures suggests that visual perception, attention and overall cognition are influenced by cultural contexts. Studies comparing western and eastern cultures present strong data showing differences on face recognition, spatial attention and other cognitive aspects. Based on those assertions, the present study proposes a reaction-time task to assess implicit cognition in children to understand the development of self-concept based on other cognitive functions such as face perception. Participated from this study 36 Brazilian children with age range of 9-to-11 years old. Participants were divided by ascendance: Japanese and Western; and paired by age and sex. An Implicit Association Test was programmed to measure the level of implicit attitude of participants towards their own and the other studied ethnicity. Results suggest that, despite of same nationality - all children were Brazilian; cultural background plays an important role on diverse cognitive domains.
\end{abstract}

Keywords: cognition, implicit association, attitude, culture

\section{Introduction}

Visual perception relies strongly on attentional performance, however attention is limited. Empirical evidence suggests that people from different cultural backgrounds tend to allocate their attentional focuses in different visual cues. For example, cognitive activity of Easterners and Westerners differ systematically, including categorization, causal explanation and logical inference versus dialectic (Nisbett, 2003; Nisbett, Peng, Shoi, \& Norezayan, 2001). According to these findings, people from Easterner Cultures (e.g., China, Korea and Japan) tend to pay more attention to contextual information than Westerners (Ji, Peng, \& Nisbett, 2000; Kitayama, Duffy, Kawamura, \& Larsen, 2003).

Nisbett et al. (2001) argue that differences in social practices can be attributed to culture. For example, the ideologies of East Asia such as Buddhism and Taoism in general, tend to emphasize that all things in the world are interconnected. In contrast, the Greek origin of the Western cultural tradition directs his efforts to understand and track the objects without worrying about the relationships among themselves or with information from the environment. These findings lead the way to the individualism versus collectivism hypothesis (Triandis, 1995). It postulates that Easterners have more collectivist cultures whereas Westerners are more individualist, more concerned about themselves rather than the whole community. Those differences between cultural backgrounds should explain group differences in cognitive tasks.

Chua, Boland, and Nisbett (2005) conducted a series of experiments using eye-tracking. The participants had to recognize one or a group of objects while looking at a complex picture. Results of these experiments showed evidence to support the culture hypothesis. American participants looked first and for a significantly longer period of time for the central objects when they appear on the computer screen, whereas Japanese participants showed significant more eyes movements toward the background of the pictures. These results demonstrated that Japanese tend to process visual images contextually, paying more attention to substance and relations, while Westerners tend to focus on salient objects and their properties. 
Nisbett and Masuda (2003) argue that social practices in East Asian cultures tend to facilitate individuals' sensitivity to social and contextual stimuli. Masuda et al. (2008) tested this assertion using an facial emotional expressions recognition task. In this experiment, participants had to judge whether each stimulus was a happy or a sad image based on facial emotional expressions of the cartoon characters. Four conditions were presented to participants: happy congruent - all characters were happy; sad congruent-all characters were sad; happy incongruent - the central-positioned character was happy and the backgound characters were sad; and sad incongruent - the central-positioned character was sad and the background characters were happy. The results showed that Japanese undergraduate students were more influenced by facial emotional expressions of the figures in the background whereas their American counterparts relied significantly more in the central-positioned character.

Cultural differences can also lead to prejudice. Wink (1997) showed that ethnicity lays an important role on the individualism versus collectivism hypothesis. In this study, data for ethnicity, individualist/collectivist attitudes, religious beliefs and personal openness toward others were collected among 453 Chineses, Korean and European undergraduate students. The results showed that Chinese and Korean students were significantly more associated to collectivism attitudes and open toward others, whereas European were more associated with individualism. Religious beliefs did not predict any variable significantly.

In another study with Hispanic-descendant and Anglo-American samples in the United States, individualism and collectivism was also assessed, as well as other social and individual variables such as: perceived personal and group discrimination, self-esteem and social dominance orientation. The results showed strong positive correlation between collectivism and perceived personal discrimination among Hispanic-descendants, whereas Anglo-Americans showed significant positive correlation between social dominance orientation and perceived group discrimination (Shorey, Cowan, \& Sullivan, 2002).

Iwao and Triandis (1993) compared individual and group acceptance of stereotyping in a sample of American and Japanese undergraduate students. In this work, auto- and heterostereotypes were examined among other variables such as personal behaviors in hypothetic situations and self-concept. The Japanese students showed significant positive correlation between heterostereotypes and self-concept, showing more passive attitudes towards inconsistencies between private-self and public-self, whereas American students tried to make their behavior more consistent between private-self and public-self, also showing positive correlation between auto-stereotyping and self-concept.

Altogether, these evidence suggest that ethnicity is linked to collectivist/individualist attitudes, and collectivists tend to feel opener toward others than individualists. Based on those two assumptions, one can assume that probably developing and living in a collectivist culture - such as Japanese, Chinese or Korean; can lead to a broader self-concept whereas developing in an individualist environment leads to a narrower and self-centered attitude. However, it is unclear when a child starts to feel more or less affiliated to a culture or whether exposure to a different cultural perspective plays a role in self-concept.

\subsection{Implicit Cognition and Cultural Prejudice}

These variations in social and cognitive processes can be assessed using the implicit cognition or attitude of an individual towards one culture. The stronger the person's affiliation to a culture, the stronger the cultural influence on the development of cognitive processes and consequently the person's behavior. Greenwald, McGhee, and Schwartz (1998) exemplified this phenomenon through the strength of the association of male names with masculine faces, in other words, it is very easy to quickly respond male names to male faces than when the person has to assign a task associating male names to female faces. Implicit attitudes are manifested through actions or judgments controlled by an automatic evaluation. Greenwald and Banaji (1995) defined implicit attitudes as "introspectively unidentified (or inaccurately identified) traces of past experience that mediate favorable or unfavorable feeling, thought or action toward social objects".

The Implicit Association Test (IAT) is a measure of spontaneous self-concept, which avoids the conscious processing of information and has been extensively used in researches. This paradigm presents better ecological validity than traditional scales in themes with moral or ethical content (Greenwald, McGhee, \& Schwartz, 1998). Greenwald and Farnham (2000) conducted a study to demonstrate that implicit measures of self-concept can hold different results when compared to explicit measures for the same domain. Through a IAT programmed to self-concept of gender, men and women showed a quadruple self-concept combination. Some men felt affiliated to masculinity, but also did some women participants, whereas the opposite also occurred toward femininity. However, those results disappeared in a explicit measure, keeping the duality of gender and self-concept. This results can be explained due to the strong social pressure by the culture. Until now, the scientific literature has 
not studied yet how implicit self-concept of children develops in children whose families come from those two different cultural types, but the child is born or raised in a particular culture.

Brazil is well-known to be a friendly and receptive country. This would imply that Brazilian culture is basically collectivist. Indeed, Smith, Dugan, Peterson, and Leung (1998) suggested that Brazil, Nigeria, Uganda and Spain presented the highest levels of collectivism among 23 countries in a exploratory study. Also, Brazil showed higher levels of collectivism when compared to the United States (Bontempo, Lobel, \& Triandis, 1990). However, those results seem to vary in Brazil depending on demographic region - urban versus rural, size of town and religious beliefs (Gouveia, Andrade, Jesus, \& Soares, 2002; Gouveia \& Clemente, 2000). In fact, Brazilian urban areas show significant higher levels of individualism than its rural areas; also big cities, such as Rio de Janeiro or Florianopolis, showed significant differences in parenting style when compared to small cities (Martins et al., 2009; Vieira et al., 2013). This differentiation in parenting can lead to more autonomous and self-centered children in urban areas in Brazil in opposite to more group-centered children such as in Japanese or other Eastern cultures.

The purpose of this paper is to investigate the influence of cultural affiliation on the implicit self-concept of 9-to-11 year-old. The hypothesis of this study - founded on previous findings already presented - is that developing in an urban area in Brazil with higher individualist levels can play a central role on the development of self-concept in those children, even if their parents come from a more collectivist culture.

\section{Method}

\subsection{Participants}

Participated of the present study 36 Brazilian children with age range of 9-11 years old, born and living at Rio de Janeiro and Niterói. Two groups were defined by ethnicity: 18 Brazilian children, and 18 Japanese-descendant children. The groups were equally paired by sex and age, whereas 9 among the 18 of each group were girls. Among those 9 children for each sex, 3 children had 9 years-old, 3 had 10 years-old and 3 had 11 years-old, thus age and sex were equally distributed inside each subgroup allowing paired inferential statistics. The Japanese-descendant children were all born and raised in Rio de Janeiro. They attended to activities at Nikkey Society, at Cosme Velho in Rio de Janeiro and at Tingá in Niterói, Brazil, but also attended regularly to Brazilian schools. The Japanese-descendant participants were selected based on a presumed length of exposure to both Brazilian and Japanese cultures. The Nikkei Society is a cultural center for spreading the Japanese culture among Japanese descendants. Children attended daily to Japanese and cultural lessons, martial arts and origami.

Brazilian children attended to one particular school: Dispensário Santa Terezinha do Menino Jesus at Gávea, Rio de Janeiro, Brazil. All participants were tested in their study environments during the regular activities. Parents had to complete and sign the Consent Form before their children participation. The study was approved by the Ethical Committee of the Pontifical Catholic University of Rio de Janeiro.

\subsection{Stimuli}

The stimuli was formed by 12 photographs of Caucasian children faces ( 6 male and 6 female photographs) and 12 photographs of Japanese children faces ( 6 male and 6 female photographs). Those images were validated in previous studies (Anzures et al., 2013; Kelly et al., 2007) and gently provided by the University of Toronto. The photographs of the faces were cut into oval-shaped with 493 pixels x 493 pixels. The images were cropped to eliminate cues such as hair, earrings, acne. The faces were exposed in a 15 inches flat screen monitor of a notebook computer Dell Latitude D505 Intel Pentium-M 1.6 Ghz.

\subsection{Procedure}

The participants were tested individually in a match to sample task programmed on the software Inquisit (Millesecond Software). We used a Self-Concept IAT to investigate children's affiliation with his own race. Two categories were programmed: self-concept (Me vs. Not-Me) and faces (Caucasian Faces vs. Japanese Faces). Figure 1 presents the Categorization task with five steps to the Implicit Associations Test (IAT) of the Race. The dots indicate the correct response filled. The IAT effect is the difference of averages in the subject's reaction times in step 3 and step 5. We calculated the IAT for the association of the categories "Me+ Japanese". Positive results indicate a stronger association for this condition, while negative results indicate a stronger association between the condition "Me+Caucasian". The order of steps 2-3 and steps 4-5 was alternated for each different participant. 
Step 1:

Practice Block (20 trials)

\begin{tabular}{|c|c|c|}
\hline $\begin{array}{c}\text { Category } \\
\text { Labels }\end{array}$ & Sample Items & $\begin{array}{c}\text { Category } \\
\text { Labels }\end{array}$ \\
\hline
\end{tabular}

Step 2:

Practice Block (20 trials)
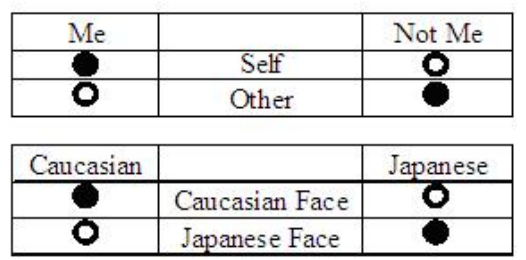

Step 3:

Practice Block (20 trials)

Critical Block (40 trials)

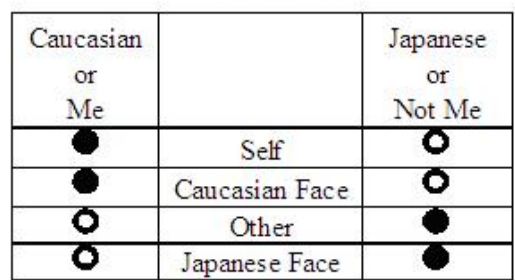

Step 4:

Practice Block (20 trials)

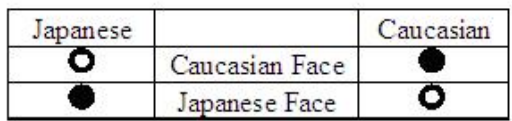

Step 5:

Practice Block (20 trials)

Critical Block (40 trials)

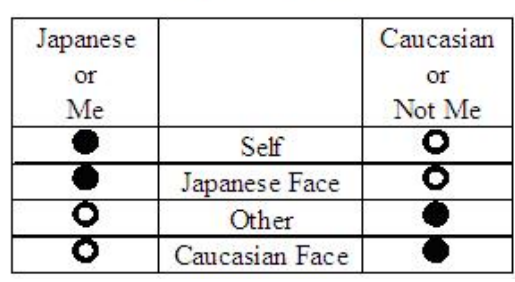

Figure 1. IAT procedure for children's attitudes towards ethnicity

\subsection{Statistical Analysis}

The D algorithm was used for data reduction following the guidelines provided by Greenwald, Nosek, and Banaji (2003). The new D algorithm replaced the old correction algorithm to obtain more consistent data from IAT procedures. Studies, since the new D algorithm, have shown more cohesive results (Lane, Banaji, Nosek, \& Greenwald, 2007). It is a simple procedure for data reduction that consists on the following steps: (1) Delete trials greater than 10,000 ms., (2) Delete subjects with more than $10 \%$ of the trials with times lowers than 300 ms. - it did not happen in the present sample, (3) Compute the Standard Deviations for Steps 3 and 5, including Practice Blocks, (4) Compute the Mean Latency for responses for Steps 3 and 5, (5) Compute two Mean Differences (Step 3 Practice Block - Step 5 Practice Block and Step 3 Critical Block - Step 5 Critical Block), (6) Divide it Mean Difference by its associated Standard Deviation, (7) Average the two resulting ratios (Lane et al., 2007). After that, a paired t-test was conducted to analyze the presence of statistical differences between groups - the Cohen's $d$ is provided for effect size purposes. 


\section{Results}

IAT Score for "Me+Japanese" Association

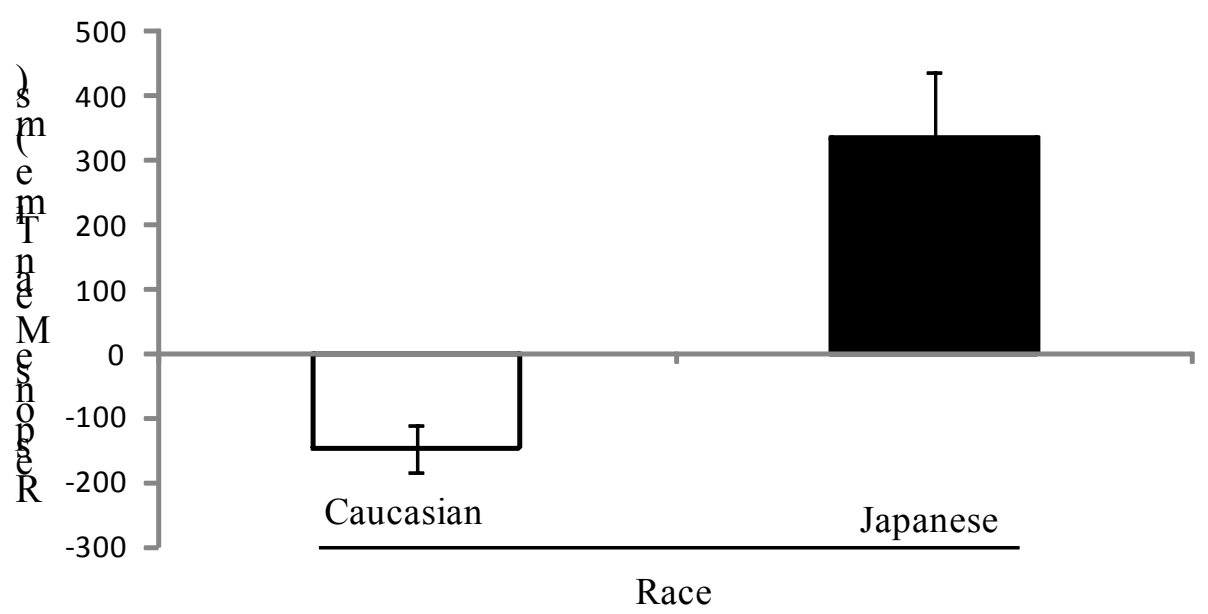

Figure 2. IAT-score based on the D algorithm (Lane et al., 2007) for association between self-concept and Japanese faces

The figure 2 holds the Mean Differences between Step 3 and Step 5 for both groups: Brazilian children obtained a Mean Difference of MD = -145.93 ms., SEM = 35.68, showing that those children had lower Response Time for the Step 3 (Me+Caucasian Block) when subtracted by their results for the Step 5 (Me+Japanese Block). Japanese children obtained a Mean Difference of MD $=333.47, \mathrm{EPM}=101.63$ that represents higher Response Time for Step 3 (Me+Caucasian Block) than Step 5 (Me+Japanese Block). Lower Response Times mean more implicit association with those categories. The results demonstrated significant differences between groups $\mathrm{t}(34)$ $=-4,616 ; p<0,001 ; d=1.23$. This result shows that even having been born in Brazil, the Japanese-descendant children felt affiliated with their culture.

\section{Discussion}

The results were partially contrary to this study's hyphotesis: that Japanese-descendant children raised in a Brazilian urban environment would be influenced of the urban individualist culture of a big city like Rio de Janeiro regarding their self-concept. In fact, Japanese-descendant children held a strong affiliation towards their own race, even bigger than the Brazilian children toward Caucasian faces. According to Gombrich's (2000), the different cultural experience exposes people to different dominant modes of visual images, creating an internalization of these standards. Some evidence supports the premise that the cultural environment affects the perception of the world. However, the results seem to pose a challenge to the individualism versus collectivism hypothesis (Triandis, 1995). If Japanese-descendant were influenced by the Brazilian urban culture, then it was expected that they would show a broader self-concept feeling associated to both Caucasian and Japanese faces - or at least their affiliation would be weaker than Brazilian children's self-concept, since they were raised in Brazil with a large amount of exposure to an urban environment.

If those results cannot be accounted by the individualism versus collectivism hypothesis, two alternative explanations are suggested: collectivism and individualism are traits of the same continuum and the Japanese culture is not as collectivist as one would expect; or self-concept is not a good measure to assess cultural affiliation.

The Japanese culture is known by its holistic features. Japanese people pay more attention to the context and is more concerned with the whole than its individual parts (Ji, Peng, \& Nisbett, 2000; Kitayama, Duffy, Kawamura, \& Larsen, 2003; Nisbett, 2003; Nisbett, Peng, Shoi, \& Norezayan, 2001). Cultural influence in cognition, however, does not necessarily lead to a collectivist culture. Focusing attention in the environment rather than the central element of a picture is not necessarily linked to the level of collectivism. Triandis (1995) explains that the collectivism is defined by several aspects and among them, being a group-centered culture, being aware of a larger sense of community and being concerned about the implications of an individual's decision in the 
community. Indeed, one aspect of collectivism is a holistic view of group, but this is only one of its several aspects. In fact, Smith et al. (1998) showed that Brazil and Japan are very similar regarding a collectivist culture when comparing them among other 21 countries in a cohort study. Graham (1985) showed similar patterns in in-group negotiation of Brazilian and Japanese when comparing both cultures to Americans.

This study suggested that Rio de Janeiro's urban environment would affect the level of collectivism of the Brazilian culture leading to a more individualist culture (Martins et al., 2009; Vieira et al., 2013). The results, on the opposite, are probably showing that even reducing the collectivist level by collecting data in an urban environment, Brazilian children still collectivists rather than individualists. This would partially explain why Brazilian and Japanese-descendant children showed the same pattern of self-concept. On the other hand, the sum of exposure to their own culture is influencing enough the Japanese-descendant children to remain affiliated to the Japanese culture.

The second hypothesis to explain data is that the self-concept IAT is a measure of racial affiliation rather than cultural affiliation. As shown by Greenwald and Franham (2000) the self-concept IAT opens the possibility of having participants affiliated to implicit social cognitions rather than rigid stereotypes. Also, evidence suggests that children recognize easier other race's faces than their own at age 5 (Bar-Haim, Ziy, Lamy, \& Hodes, 2006; Carey, Diamond, \& Woods, 1980). The present data was collected in Brazilian children with or without Japanese ascendants, thus, founded in Greenwald and Farnham (2000) results, a broader and more flexible self-concept was expected among Japanese-descendant - here represented by negative MD toward "Me+Japanese". However, culture indeed seemed to play an important role on self-concept and attitude towards their own race because Japanese-descendant children actually showed a strong relationship between them and the self-concept of Japanese faces. Based on the results, then the present study indeed measured cultural affiliation, however other measures could have been used to validate the assessed construct.

\subsection{The Importance of Studying in Various Cultural Contexts}

It is very important to highlight that those researches are conducted under the current trend in developmental psychology to use participants from the United States, Europe, Australia and New Zealand (Tomlinson \& Swartz, 2004). Around 135 million babies are born worldwide every year and near ninety percent of those babies are from countries outside this Western axis. Heinrich, Heine, and Norenzayan (2010) point to the erroneous generalization of those studies' results, since their samples consist of WEIRD participants (western, educated, industrialized, rich and democratic). Seidl-de-Moura (2011) points out that those studies' characteristic pose as a serious problem for the science of human development in general and developmental psychology. If, according to Masuda and Nisbett (2001), cultural patterns in which the individual was raised, affect the perception processes (e.g., Easterners tend to perceive in a more holistic view, paying more attention in background standards; while Westerners tend to focus more on their perception of the salient object), thus we cannot generalize the results of weird samples in researches on social cognition.

Seidl-de-Moura (2011) points out to the fact that development of evolutionary psychology is a psychology based on the relationship between biology and culture. The main goal are universal psychological processes, developed in specific socio-cultural and ecological contexts. Our results presented an advance to the field of developmental psychology, providing insights about the influence of cultural contexts to self-concept in children.

\subsection{Limitations and Future Studies}

The present study was limited is some aspects. Among them, the sample size, despite of the paired sample, could pose as a difficulty to generalize results. Another issue was using only one measure that could either measure racial or cultural affiliation. It is not possible to be sure that the results are indeed reflecting the child's cultural self-concept, and, in extent, whether it is influenced by a collectivist or individualist culture. If Brazil and Japan indeed are collectivists, then the assumption initially proposed by this study that large urban centers such as Rio de Janeiro are individualist is not true. In this case, this study would benefit with a collectivism/individualism assessment to measure the level of association between those cultural aspects and children's affiliation. Finally, the construct validity of the Self-Concept IAT is not clear, thus it would be recommended to conduct a psychometric study with a larger sample and other measures to understand what was really measured in the present study.

\section{Acknowledgements}

The authors would like to thank Professor Kang Lee of the Institute for Child Studies at the University of Toronto, Canada, for providing the pictures used on this experiment. Also thanks to the Nikkei Society for its opening doors during data collection. 


\section{References}

Anzures, G., Quinn, P. C., Pascalis, O., Slater, A. M., Tanaka, J. W., \& Lee, K. (2013). Developmental Origins of the Other-Race Effect. Current Directions in Psychological Science, 22(3), 173-178. http://dx.doi.org/10.1177/0963721412474459

Bar-Haim, Y., Ziv, T., Lamy, D., \& Hodes, R. M. (2006). Nature and nurture in own-race face processing. Psychological Science, 17, 159-163. http://dx.doi.org/10.1111/j.1467-9280.2006.01679.x

Bontempo, R., Lobel, S., \& Triandis, H. (1990). Compliance and Value Internalization in Brazil and the U.S.: Effects of Allocentrism and Anonymity. Journal of Cross-Cultural Psychology, 21(2), 200-213. http://dx.doi.org/10.1177/0022022190212004

Carey, S., Diamond, R., \& Woods, B. (1980). Development of face recognition: A maturational component? Developmental Psychology, 16, 257-269. http://dx.doi.org/10.1037/0012-1649.16.4.257

Chua, H. F., Boland, J., \& Nisbett, R. E. (2005). Cultural variation in eye movements during scene perception. Proceedings of the National Academy of Sciences of the United States of America-PNAS, 102, 12629-12633. http://dx.doi.org/10.1073/pnas.0506162102

Gombrich, E. H. (2000). Art and illusion: A study in the psychology of pictorial representation (2nd ed.). Princeton, NJ: Princeton University Press.

Gouveia, V. V., Andrade, J. M. de, Jesus, G. R. de, \& Soares, M. M. E. N. F. (2002). Escala Multi-fatorial de Individualismo e Coletivismo: Elaboração e Validação de Construto. [Multifactorial Scale of Individualism and Collectivism: Development and Construct Validity]. Psicologia: Teoria E Pesquisa, 18(2), 203-212. http://dx.doi.org/10.1590/S0102-37722002000200010

Gouveia, V. V., \& Clemente, M. (2000). O individualismo-coletivismo no Brasil e na Espanha: Correlatos sócio-demográficos. [The individualism-collectivism in Brazil and Spain: Sociodemographic correlations]. Estudos de Psicologia, 5(2), 317-346. http://dx.doi.org/10.1590/S1413-294X2000000200003

Graham, J. L. (1985). The Influence of Culture on the Process of Business Negotiations: An Exploratory Study. Journal of International Business Studies, 16(1), 81-96. http://dx.doi.org/10.1057/palgrave.jibs.8490443

Greenwald, A. G., \& Banaji, M. R. (1995). Implicit social cognition: Attitudes, self-esteem, and stereotypes. Psychological Review, 102, 4-27. http://dx.doi.org/10.1037/0033-295X.102.1.4

Greenwald, A. G., \& Farnham, S. D. (2000). Using the Implicit Association Test to measure self-esteem and self-concept. Journal of Personality and Social Psychology, 79, 1022-1038. http://dx.doi.org/10.1037/0022-3514.79.6.1022

Greenwald, A. G., McGhee, D. E., \& Schwartz, J. L. K. (1998). Measuring individual differences in implicit cognition: The Implicit Association Test. Journal of Personality and Social Psychology, 74, 1464-1480. http://dx.doi.org/10.1037/0022-3514.74.6.1464

Greenwald, A. G., Nosek, B. A., \& Banaji, M. R. (2003). Understanding and using the Implicit Association Test: I. An improved scoring algorithm. Journal of Personality and Social Psychology, 85, 197-216. http://dx.doi.org/10.1037/0022-3514.85.2.197

Henrich, J., Heine, S. J. J., \& Norenzayan, A. (2010). The weirdest people in the world? Behavioral and Brain Sciences, 33, 61-135. http://dx.doi.org/10.1017/S0140525X0999152X

Iwao, S., \& Triandis, H. C. (1993). Validity of Auto- and Heterostereotypes among Japanese and American $\begin{array}{lllll}\text { Students. Journal of } & \text { Cross-Cultural }\end{array}$ http://dx.doi.org/10.1177/0022022193244004

Lane, K. A., Banaji, M. R., Nosek, B. A., \& Greenwald, A. G. (2007). Understanding and using the Implicit Association Test: IV. What we know (so far) (pp. 59-102). In B. Wittenbrink, \& N. S. Schwarz (Eds.), Implicit measures of attitudes: Procedures and controversies. New York, NY: Guilford Press.

Ji, L., Peng, K., \& Nisbett, R. E. (2000). Culture, control, and perception of relationships in the environment. Journal of Personality and Social Psychology, 78, 943-955. http://dx.doi.org/10.1037/0022-3514.78.5.943

Kelly, D. J., Quinn, P. C., Slater, A. M., Lee, K., Ge, L., \& Pascalis, O. (2007). The other-race effect develops during infancy: Evidence of perceptual narrowing. Psychological Science, 18(12), 1084-1089. http://dx.doi.org/10.1111/j.1467-9280.2007.02029.x 
Kitayama, S., Duffy, S., Kawamura, T., \& Larsen, J. T. (2003). Perceiving an object and its context in different cultures: A cultural look at the New Look. Psychological Science, 14, 201-206. http://dx.doi.org/10.1111/1467-9280.02432

Martins, G. D. F., Macarini, S. M., Vieira, M. L., Sachetti, V. A. R., Seidl-de-Moura, M. L., \& Bussab, V. S. R. (2009). Cuidado parental e apoio social em mães residentes na capital e interior de Santa Catarina [Parental Care and Social Support in mothers from the capital and interior of Santa Catarina]. Interação Em Psicologia, 13(1), 25-35.

Masuda, T., Ellsworth, P., Mesquita, B., Leu, J-.X., Tanida, S., \& Van de Veerdon, E. (2008). Placing the face in context: Cultural differences in the perception of facial emotion. Journal of Personality and Social Psychology, 94, 365-381. http://dx.doi.org/10.1037/0022-3514.94.3.365

Masuda, T., \& Nisbett, R. E. (2001). Attending holistically vs. analytically: Comparing the context sensitivity of Japanese and Americans. Journal of Personality and Social Psychology, 81, 922-934. http://dx.doi.org/10.1037/0022-3514.81.5.922

Markus, H. R., \& Kitayama, S. (1991). Culture and the self: Implications for cognition, emotion, and motivation. Psychological Review, 98, 224-253. http://dx.doi.org/10.1037/0033-295X.98.2.224

Nisbett, R. E. (2003). The geography of thought: How Asians and Westerners think differently ... and why. New York: Free Press.

Nisbett, R. E., \& Masuda, T. (2003). Culture and point of view. Proceedings of the National Academy of Sciences of the United States of America-PNAS, 100, 11163-11175. http://dx.doi.org/10.1073/pnas.1934527100

Nisbett, R. E., Peng, K, Choi, I., \& Norenzayan, A. (2001). Culture and systems of thought: Holistic vs. analytic cognition. Psychological Review, 108, 291-310. http://dx.doi.org/10.1037/0033-295X.108.2.291

Shorey, H. S., Cowan, G., \& Sullivan, M. P. (2002). Predicting Perceptions of Discrimination among Hispanics and Anglos. Hispanic Journal of Behavioral Sciences, 24(1), 3-22. http://dx.doi.org/10.1177/0739986302024001001

Smith, P. B., Dugan, S., Peterson, A. F., \& Leung, W. (1998). Individualism: Collectivism and the handling of disagreement. A 23 country study. International Journal of Intercultural Relations, 22(3), 351-367. http://dx.doi.org/10.1016/S0147-1767(98)00012-1

Tomlinson, M., \& Swartz, L. (2003). Representing infancy across the world: Does Osama bin Laden love his children. Culture \& Psychology, 9(4), 487-497. http://dx.doi.org/10.1177/1354067X0394012

Triandis, H. C. (1995). Individualism and collectivism. Boulder, CO: Westview.

Vieira, M. L., Seidl-de-Moura, M. L., Macarini, S. M., Martins, G. D. F., Lordelo, E. da R., Tokumaru, R. S., \& Oliva, Â. D. (2013). Autonomy and Interdependence: Beliefs of Brazilian Mothers from State Capitals and Small Towns. The Spanish Journal of Psychology, 13(2), 818-826. http://dx.doi.org/10.1017/S113874160000247X

Wink, P. (1997). Beyond Ethnic Differences: Contextualizing the Influence of Ethnicity on Individualism and $\begin{array}{lllll}\text { Collectivism. } & \text { Journal of } & \text { Social } & \text { Issues, } & 53(2),\end{array}$ http://dx.doi.org/10.1111/j.1540-4560.1997.tb02446.x

\section{Copyrights}

Copyright for this article is retained by the author(s), with first publication rights granted to the journal.

This is an open-access article distributed under the terms and conditions of the Creative Commons Attribution license (http://creativecommons.org/licenses/by/3.0/). 